\title{
Atoh1 expression levels define the fate of rat cochlear nonsensory epithelial cells in vitro
}

\author{
WEN-WEI LUO* ${ }^{*}$ JUAN-MEI YANG* ${ }^{*}$ ZHAO HAN, YA-SHENG YUAN, \\ HAI-BIN SHENG, XIANG LIU and FANG-LU CHI
}

\begin{abstract}
Department of Otolaryngology-Head and Neck Surgery, Eye and ENT Hospital of Fudan University, Xuhui, Shanghai 200031, P.R. China
\end{abstract}

Received September 21, 2013; Accepted March 3, 2014

DOI: $10.3892 / \mathrm{mmr} .2014 .2202$

\begin{abstract}
Atonal homolog 1 (Atoh1) is a basic helix-loop-helix transcription factor that is essential for inner ear hair cell differentiation. Previous studies have reported that Atoh1 gene transfer induces the production of ectopic hair cell-like cells (EHCLCs). In the present study, the effect of different Atoh1 expression levels and the duration of EHCLC formation on the lesser epithelial ridge (LER) of cochleae was examined using a human adenovirus serotype 5 (Ad5) vector encoding atohl and the reporter gene EGFP. Different Ad5-EGFP-atoh1/Ad5-EGFP virus titers were added to cultured cochlear explants and EHCLCs were detected in the LER at various time points. The results demonstrated that GFP alone did not induce EHCLCs. By contrast, Atoh1 expression induced EHCLCs as early as 2.5-5 days following EGFP-atohl infection in the LER and depending upon the viral titer, the number of EHCLCs increased with time. Higher Ad5-EGFP-atoh1 titers induced enhanced Atoh1 expression, resulting in an increase in EHCLCs. Lower Ad5-EGFP-atoh1 titers required more time for EHCLC formation and very low titers of Ad5-EGFP-atoh1 induced only weak Atoh1 expression and did not trigger EHCLC formation. In conclusion, the present study utilized an appropriate Ad5-EGFP-atohl titer range to induce Atoh1 expression and the subsequent production of EHCLCs. The results revealed that the Atoh1 expression level defined the fate of LER cells as either EHCLCs or nonsensory epithelial cells. This evidence may provide an important guideline for future studies into gene therapy strategies for the treatment of deafness.
\end{abstract}

Correspondence to: Professor Fang-Lu Chi, Department of Otolaryngology-Head and Neck Surgery, Eye and ENT Hospital of Fudan University, no. 83 Fenyang Road, Xuhui, Shanghai 200031, P.R. China

E-mail: chifanglu@126.com

*Contributed equally

Key words: Atoh1 expression level, ectopic hair cell-like cells, lesser epithelial ridge, virus titer

\section{Introduction}

Hair cells (HCs) transform sound and balance signals into electrical impulses in the cochlear and vestibular end organs. By contrast to vertebrates that are able to spontaneously regenerate new hair and supporting cells $(1,2)$, there is no effective way to stimulate their regeneration in mammals once hair cells have been damaged by noise, ototoxic drugs or aging, which hampers the treatment of sensorin, a neural hearing impairment that is caused by hair cell loss.

Atoh1 is a basic helix-loop-helix transcription factor that is crucial in hair cell formation $(3,4)$. Knockout of atohl in mice results in the absence of differentiated hair cells and supporting cells, while Atoh1 overexpression in cultured explants or in vivo induces ectopic hair cell-like cell (EHCLC) formation (3,5-14).

Studies in a novel atohl 'self-terminating' mouse model have suggested that Atoh1 expression level and duration is crucial for inner and outer hair cell differentiation in vivo (15). Therefore, we aimed to investigate how Atoh1 affects EHCLC formation and whether Atoh1 expression defines the fate of LER cells as either ectopic, newly formed hair cells or nonsensory epithelial cells. In the present study, cultured explants were infected with several virus titers and EHCLC expression was detected in the LER at different time points. It was identified that the formation of EHCLCs was Atoh1 dependent, as no EHCLCs formed upon infection by GFP alone. Following LER infection with an appropriate titer (EGFP-atohl) for Atoh1 expression (1.6x10 $\mathrm{PFU} / \mathrm{ml})$, EHCLC production was detected as early as 2.5 days and the number of EHCLCs increased with time. Higher Ad5-EGFP-atoh1 titers induced increased Atoh1 expression and a larger quantity of hair cell-like cells appeared at earlier time points compared with lower titers. Lower Ad5-EGFP-atohl titers induced less Atoh1 expression and required a greater duration for EHCLC formation. Extremely low Ad5-EGFP-atohl titers induced only weak Atoh1 expression and no formation of EHCLCs. Therefore, Atoh1 expression levels define the fate of LER cells as either EHCLCs or nonsensory epithelial cells, and greater Atoh1 expression decreases the time required for EHCLC formation in the LER. These data define an appropriate Ad5-EGFP-atohl titer range for ectopic hair cell formation and which will act as an important guideline for future studies. 

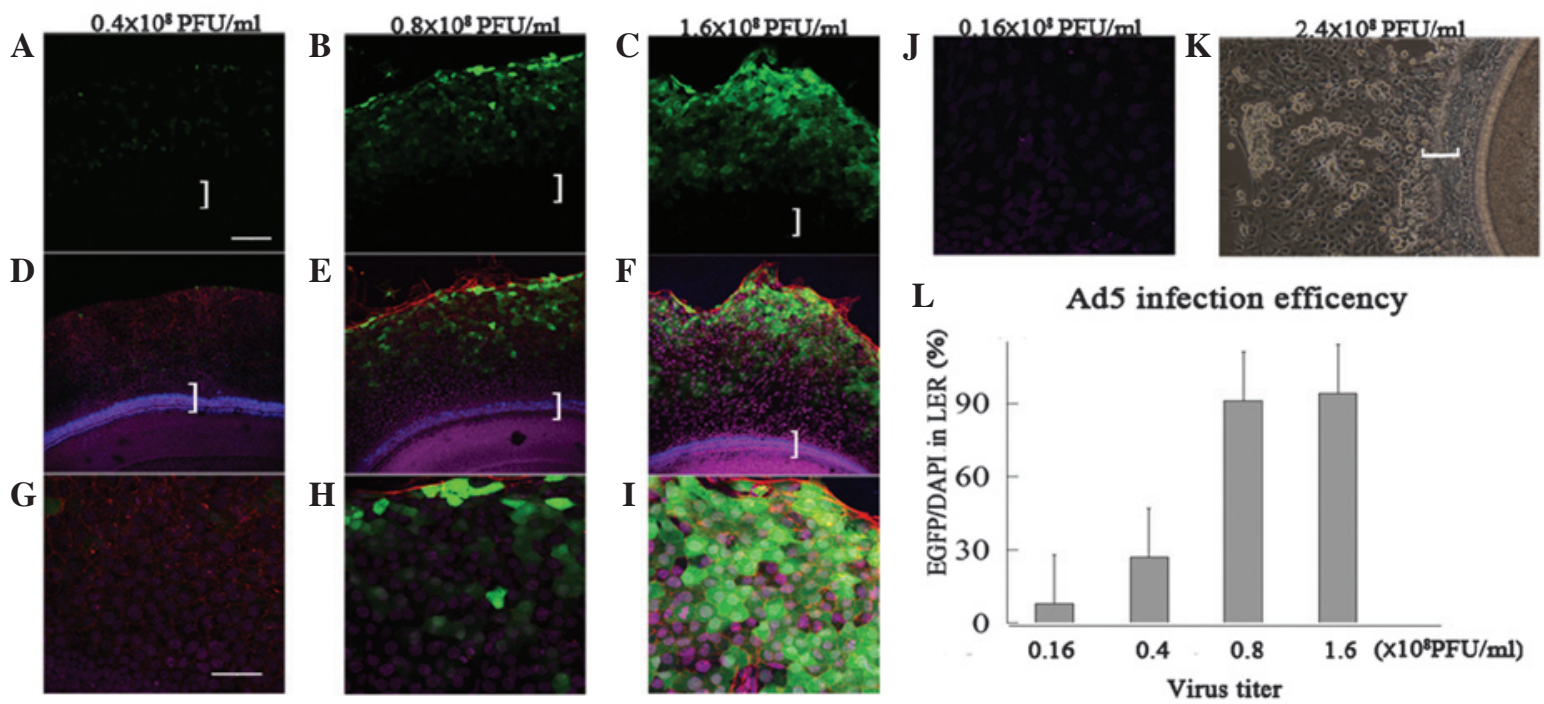

Figure 1. Different Ad5 vector infection rates in the LER at different titers. (A and D) At $0.4 \times 10^{8} \mathrm{PFU} / \mathrm{ml}$, a number of LER cells were GFP positive with moderate green fluorescence. (B and E) At $0.8 \times 10^{8} \mathrm{PFU} / \mathrm{ml}$, the majority of LER cells were GFP positive with moderate to strong green fluorescence. (C and F) Following infection at 1.6x10 $\mathrm{PFU} / \mathrm{ml}$, the majority of LER cells were GFP positive with strong green fluorescence. (G-I) Magnified views of (D), (E) and (F). (J) Following infection at $0.16 \times 10^{8} \mathrm{PFU} / \mathrm{ml}$, sporadic cells were GFP positive with weak green fluorescence. (K) Following infection at $2.4 \times 10^{8} \mathrm{PFU} / \mathrm{ml}$, the virus damaged the cochlear explants. (L) Histogram of the Ad5-EGFP-atohl/Ad5-EGFP infection rate (x-axis, virus titer; $\mathrm{y}$-axis, number of GFP/ number of DAPI). Green, GFP; blue, myosin7A; purple, DAPI. Scale: A-F, $100 \mu \mathrm{m}$; G-J, $50 \mu \mathrm{m}$. White brackets indicate the sensory epithelium. LER, lesser epithelial ridge; Ad5, human adenovirus serotype 5.

\section{Materials and methods}

Cultures of postnatal rat cochleae and atohl gene infection. This study was approved by the Institutional Animal Care and Animal Ethics Committee of Fudan University (Xuhui, Shanghai, China). One-day-old postnatal (P1) SD rats were used for the experiments and were purchased from Slaccas Experimental Animal Company (Xuhui, Shanghai, China). The rats were sacrificed by $\mathrm{CO}_{2}$ asphyxiation. The cochlear explants culture was prepared as described previously $(11,12)$. The final concentrations of the Ad5-EGFP-atohl vector were $0.1 \times 10^{8}$, $0.4 \times 10^{8}, 0.8 \times 10^{8}, 1.6 \times 10^{8}$ and $2.4 \times 10^{8} \mathrm{PFU} / \mathrm{ml}$ in serum-free DMEM/F12. The control group (Ad5-EGFP) included corresponding titers. The viruses used were as described previously $(6,7,11,12)$

Tissue preparation and immunofluorescence. The cochlear explants were fixed with $4 \%$ paraformaldehyde for $30 \mathrm{~min}$ and then treated with $0.1 \%$ Triton X-100 plus $10 \%$ donkey serum for $30 \mathrm{~min}$. Following this, the explants were incubated with the following primary antibodies for $24 \mathrm{~h}$ at $4^{\circ} \mathrm{C}$; myosin7A (1:100; Proteus Biosciences Inc., Ramona, CA, USA), myosin7A (1:200; Developmental Studies Hybridoma Bank, Iowa City, IA, USA), p27kip1 (1:100; Cell Signaling Technology, Inc., CA, USA) and Sox2 (1:300, Santa Cruz Biotechnology, Inc, Santa Cruz, CA, USA). The preparation was washed 3-5 times in PBS and then incubated with secondary antibodies for $2 \mathrm{~h}$ at $37^{\circ} \mathrm{C}$ in the dark. The secondary antibodies included donkey anti-mouse/rabbit Alexa Fluor $555(1: 1,000)$ and/or donkey anti-mouse/rabbit/goat $(\mathrm{H}+\mathrm{L})$ Alexa Fluor 647 (1:1,000; Molecular Probes, Invitrogen Life Technologies, Carlsbad, CA, USA). The specimens were visualized with a Zeiss LSM 510 confocal laser-scanning microscope (Carl Zeiss, Oberkochen, Germany) and only one image was captured by the microscope.
Cell counting and statistical analysis. Only cells at the LER region of the mid-basal turns were counted. Using random samples, the cells in $200 \mu \mathrm{m}$ segments along the length of the cochlea were counted. Each group had at least five different cochlear explants and each explant was sampled at five areas. Ectopic hair cells were counted 3, 5, 7, 9 and 11 days post-infection. All the cell count was precisely performed by manually analyzing the confocal images. The values are expressed as the mean \pm standard error and using a one-way ANOVA statistical test when appropriate. $\mathrm{P}<0.05$ was considered to indicate a statistically significant difference.

\section{Results}

Ad5 vector transfection efficiency in the LER. The Ad5-EGFP/Ad5-EGFP-atoh1 transfection efficiency in the LER (outside of the outer hair cells) was determined by infection with different virus titers (Fig. 1). At a titer of $0.16 \times 10^{8} \mathrm{PFU} / \mathrm{ml}$, only $8 \pm 2 \%$ of LER cells were GFP positive with weak green fluorescence (Fig. 1J). At a titer of $0.4 \times 10^{8} \mathrm{PFU} / \mathrm{ml}, 27 \pm 4 \%$ of LER cells were GFP positive with moderate green fluorescence (Fig. 1A and 1D and 1G). At $0.8 \times 10^{8} \mathrm{PFU} / \mathrm{ml}, 91 \pm 7 \%$ of LER cells were GFP positive with moderate-to-strong green fluorescence (Fig. 1B and 1E and 1H). At 1.6x $10^{8} \mathrm{PFU} / \mathrm{ml}, 94 \pm 9 \%$ of LER cells were GFP positive with strong green fluorescence (Fig. $1 \mathrm{C}$ and $1 \mathrm{~F}$ and $1 \mathrm{I}$ ). However, when $2.4 \times 10^{8} \mathrm{PFU} / \mathrm{ml}$ was used, the cultured explants disintegrated (Fig. 1K). Higher viral infection efficiency was observed with increasing titer, because the transfection efficiency of $0.4 \times 10^{8} \mathrm{PFU} / \mathrm{ml}$ was significantly higher than that of $0.16 \times 10^{8} \mathrm{PFU} / \mathrm{ml}(\mathrm{n}=5, \mathrm{P}<0.05)$ and that of $0.8 \times 10^{8} \mathrm{PFU} / \mathrm{ml}$ was significantly higher than that of $0.4 \times 10^{8} \mathrm{PFU} / \mathrm{ml}(\mathrm{n}=5, \mathrm{P}<0.05)$, whereas the transfection efficiency of $1.6 \times 10^{8} \mathrm{PFU} / \mathrm{ml}$ was similar to $0.8 \times 10^{8} \mathrm{PFU} / \mathrm{ml}(\mathrm{n}=5$, $\mathrm{P}>0.05)$. However, the fluorescence intensity at $1.6 \times 10^{8} \mathrm{PFU} / \mathrm{ml}$ 


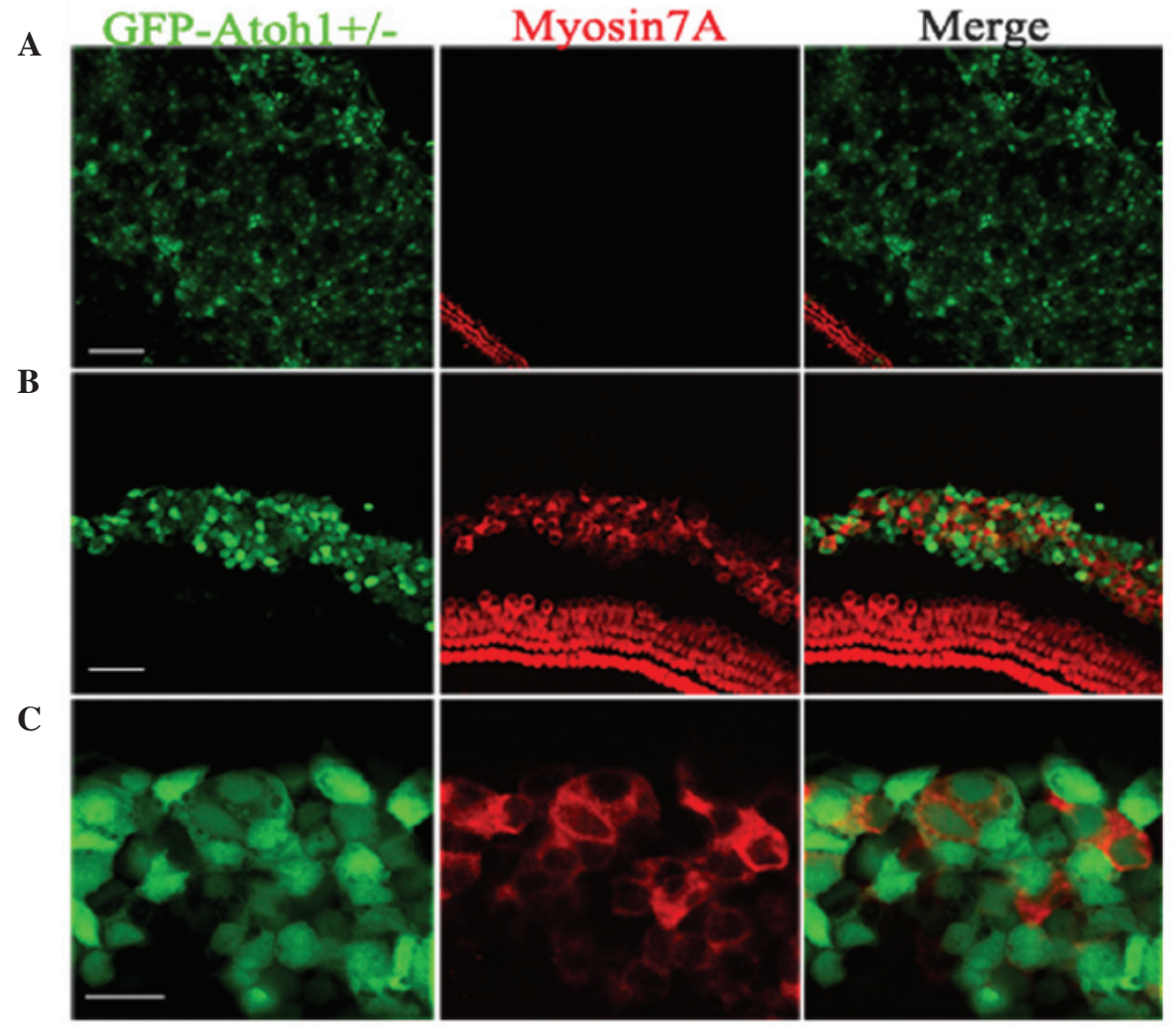

Figure 2. The formation of new EHCLCs at the LER is Atoh1 dependent. Cultured cochlear explants five days following Ad5-EGFP/Ad5-EGFP-atoh1 infection. (A) Ad5-EGFP (green: GFP) did not induce myosin7A (red)-positive cells in the LER. (B) Ad5-EGFP-atoh1 (green: GFP-Atoh1) induced numerous myosin7A (red)-positive cells in the LER. (C) Magnified images from (B). Scale bar: $100 \mu \mathrm{m}$ in (A) and (B); $50 \mu \mathrm{m}$ in (C). EHCLCs, ectopic hair-cell-like cells; LER, lesser epithelial ridge; Atoh1, Atonal homolog1; Ad5, human adenovirus serotype 5.

was higher than at $0.8 \times 10^{8} \mathrm{PFU} / \mathrm{ml}$. Therefore, it was concluded that the most effective virus titer was $1.6 \times 10^{8} \mathrm{PFU} / \mathrm{ml}$.

Formation of new EHCLCs at the LER is Atohl dependent. Following Ad-EGFP infection of the cultured explants (Fig. 2A), the LER cells presented robust EGFP fluorescence, however no myosin7A-positive cells were observed. The LER cells were unable to differentiate into hair cells. Following Ad5-EGFP-atohl infection, the LER was the target (Fig. 1B). Consistent with previous studies $(11,14)$, Ad5-EGFP-atohl infection resulted in the induction of myosin7A-positive cells in the LER regions (Fig. 2B), suggesting that these newly formed hair cells were Atoh1 overexpression dependent. Many of the EGFP-positive cells were myosin7A negative, despite having been infected with Ad5-EGFP-atohl. To determine whether the Atoh1 expression level or duration led to this phenomenon, different Ad5-EGFP-atohl titers were utilized, and the quantities and percentages of new hair cells were detected at different time points in the following study.

EHCLC formation requires a certain Atohl expression level. To address whether new EHCLC formation depends on Atoh1 expression,cultured explants were treated with Ad-EGFP-atohl at four different titers: $0.16 \times 10^{8}, 0.4 \times 10^{8}, 0.8 \times 10^{8}$ and $1.6 \times 10^{8} \mathrm{PFU} / \mathrm{ml}$. The samples were fixed at five days following viral infection (DVI) and the numbers of EGFP-myosin7A double-positive cells and EGFP-positive cells were counted

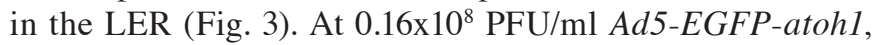

no myosin7A-positive cells were detected, implying that low Atoh1 expression was unable to induce hair-cell-like cell formation $(\mathrm{n}=5)$. At $0.4 \times 10^{8} \mathrm{PFU} / \mathrm{ml}$ Ad5-EGFP-atohl, there were $5 \pm 2$ myosin7A-EGFP double-positive cells per $200 \mu \mathrm{m}$ in the LER ( $4 \pm 3 \%$ of all EGFP-positive cells). At $0.8 \times 10^{8} \mathrm{PFU} / \mathrm{ml}$ Ad5-EGFP-atohl, there were $22 \pm 4$ myosin7A-EGFP double-positive cells per $200 \mu \mathrm{m}$ in the LER (14 $\pm 5 \%$ of all EGFP-positive cells). At $1.6 \times 10^{8}$ PFU/ml Ad5-EGFP-atohl, there were 54 \pm 4 myosin7A-EGFP double-positive cells per $200 \mu \mathrm{m}$ in LER $(57 \pm 13 \%$ of all EGFP-positive cells; $n=5)$. The number of EHCLCs in the higher virus titer groups was significantly greater compared with the lower virus titer groups (Fig. 2B). Furthermore, the LER to hair cell-like cell conversion rate was significantly enhanced in the higher than in the lower virus titer group. These data demonstrate that increasing the virus titer increased Atoh1 expression and this subsequently increased the myosin7A-positive cell number in the LER. If Atoh1 expression was too low, few LER cells converted to hair-cell-like cells. Thus, EHCLCs production was dependent on specific Atoh1 expression levels.

Higher Atohl expression reduces the duration of EHCLC formation in the LER. The number of Atoh1-induced EHCLCs increased with time. When applied to cultured explants with $0.16 \times 10^{8} \mathrm{PFU} / \mathrm{ml}$ Ad5-EGFP-atoh1, no myosin-positive cells were detected even at 11 DVI. At $0.4 \times 10^{8} \mathrm{PFU} / \mathrm{ml}$ Ad5-EGFP-atoh1, 5 \pm 2 EHCLCs per 

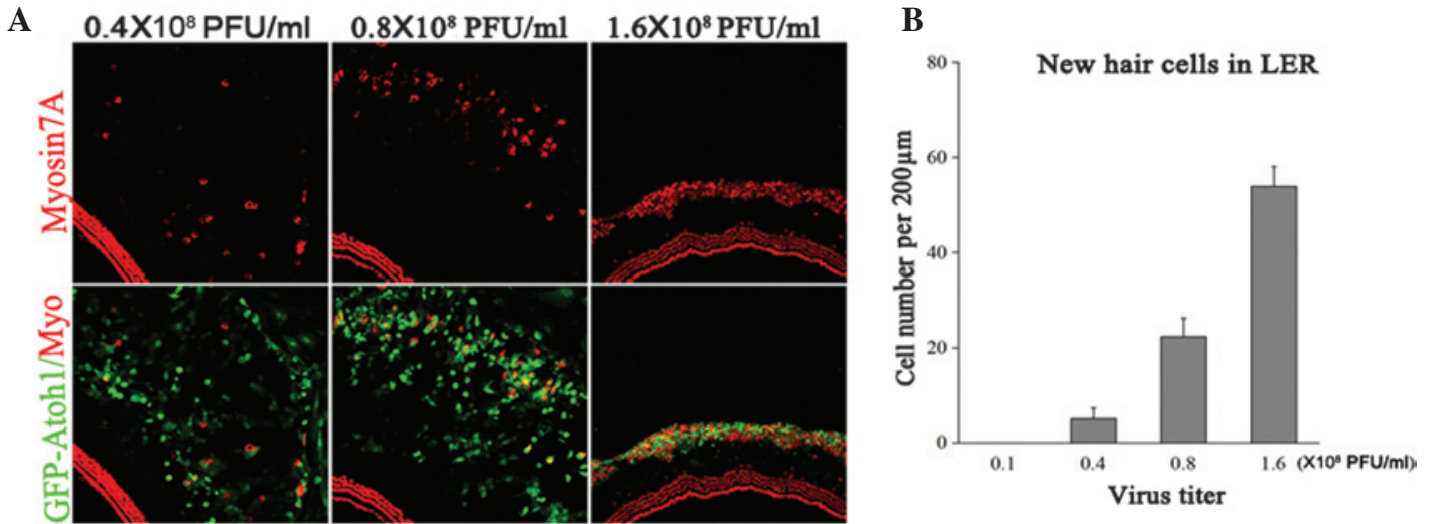

Figure 3. Higher Atoh1 expression levels induced the formation of more EHCLCs in the LER 5 DVI following Ad-EGFP-atohl infection. (A) Increasing the viral titer led to higher Atoh1 expression (GFP: green) and induced more myosin7a-positive (red) cells in the LER. (B) A bar graph illustrates the correlation between the virus titer and the number of ectopic hair cells. The cells in $200 \mu \mathrm{m}$ segments along the length of the cochlea were counted. Scale bar: $100 \mu \mathrm{m}$ in (A). Atoh1, Atonal homolog1; EHCLCs, ectopic hair-cell-like cells; LER, lesser epithelial ridge; Ad5, human adenovirus serotype 5; DVI, days after viral infection.
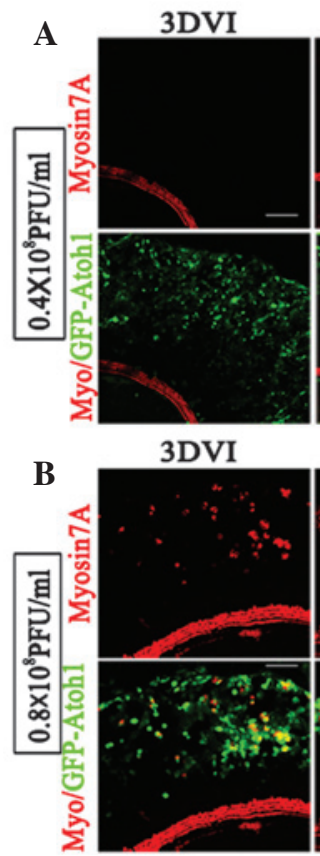

5DVI

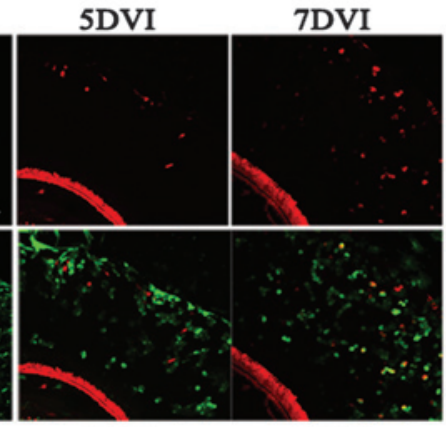

5DVI

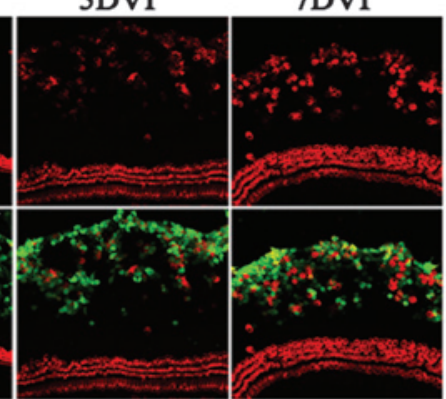

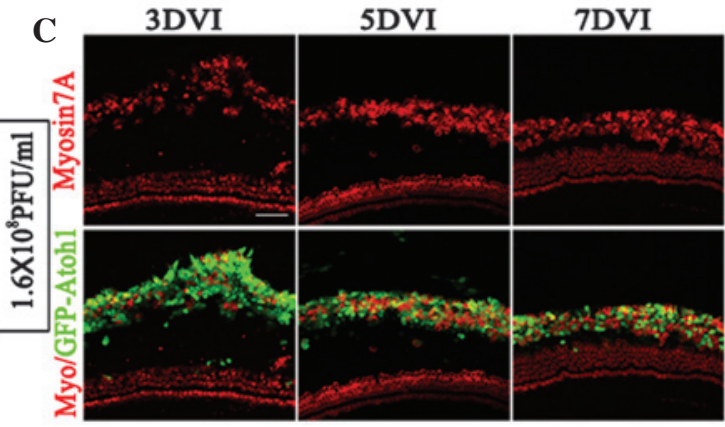

New hair cells in LER

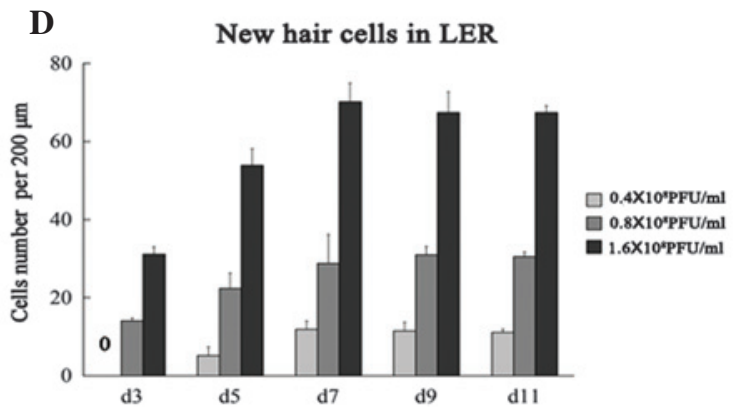

Figure 4. Higher Atoh1 expression levels reduced the duration of EHCLCs formation in the LER. (A) Explants following Ad-EGFP-atoh1 infection at

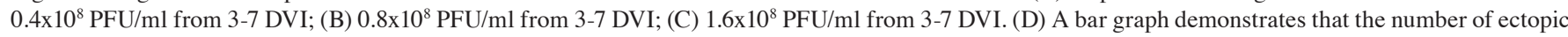
hair cells increases with time from 7-10 DVI, at different titers [x-axis: days after virus infection (virus titer); y-axis: number of EHCLCs]. Scale bar: $100 \mu$ m in (A), (B) and (C). Atoh1, Atonal homolog1; EHCLCs, ectopic hair-cell-like cells; LER, lesser epithelial ridge; Ad5, human adenovirus serotype 5; DVI, days after viral infection.

$200 \mu \mathrm{m}$ were detected as early as 5 DVI in the LER, which increased to $12 \pm 2$ at 7 DVI, $11 \pm 2$ at 9 DVI and $11 \pm 1$ at $11 \mathrm{DVI}$ (Fig. 4A and D). At $0.8 \times 10^{8} \mathrm{PFU} / \mathrm{ml}$ Ad5-EGFP-atohl, 14+1 EHCLCs per $200 \mu \mathrm{m}$ were detected as early as 3 DVI in the LER, which increased at $22 \pm 4$ on 5 DVI, $29 \pm 7$ at 7 DVI, $31 \pm 2$ at 9 DVI and $31 \pm 1$ at 11 DVI (Fig. 4B and D). At $1.6 \times 10^{8}$ PFU/ml Ad5-EGFP-atoh1, we detected myosin7A-positive cells as early as $60 \mathrm{~h}$ following atohl infection, 31 2 EHCLCs per $200 \mu \mathrm{m}$ were detected at 3 DVI in the LER, which increased to $54 \pm 4$ on 5 DVI, $70 \pm 5$ on 7 DVI, $67 \pm 6$ on 9 DVI and $67 \pm 2$ on 11 DVI (Fig. $4 \mathrm{C}$ and D). Therefore, at a low titer $\left(0.4 \times 10^{8} \mathrm{PFU} / \mathrm{ml}\right)$ with low Atoh1 expression, EHCLC formation required a longer time (5 days). At a higher titer $\left(1.6 \times 10^{8} \mathrm{PFU} / \mathrm{ml}\right)$ with high Atoh1 expression, however, EHCLC formation required only 2.5 days. EHCLCs increased with time but remained constant from 7-11 days in all groups (Fig. 4D). In conclusion, the Atoh1 expression level critically affected the time required for EHCLC formation.

Atohl expression defines the fate of LER cells. The data indicated that the number of Atoh1-induced EHCLCs increased with time but this effect ceased at 7-11 days, regardless of the titer (Fig. 4D). Despite infection of cultured cochlear explants with $A d$-EGFP-atohl at $1.6 \times 10^{8} \mathrm{PFU} / \mathrm{ml}$, only $\sim 71 \%$ of infected cells in the LER were able to transdifferentiate into hair cell-like cells. Following Ad-EGFP-atohl infection, a 


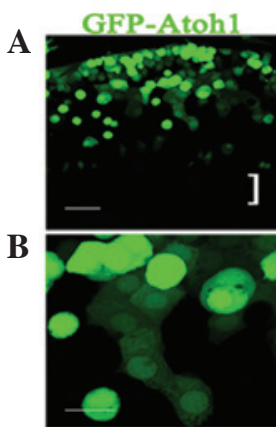

GFP-Atoh 1

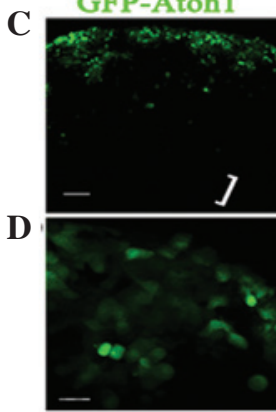

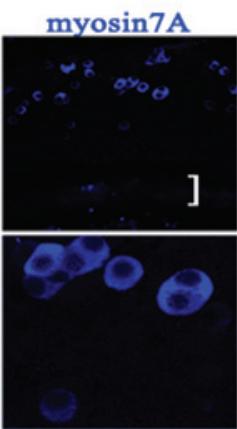

myosin $7 \mathrm{~A}$

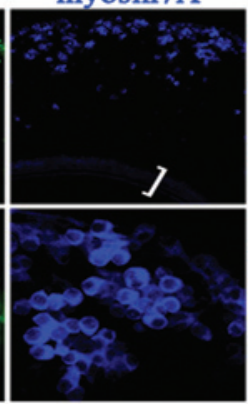

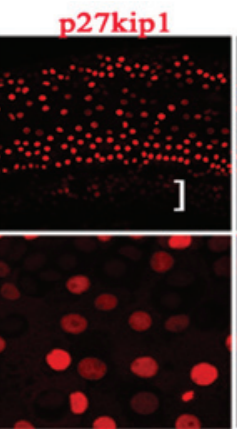

sox 2

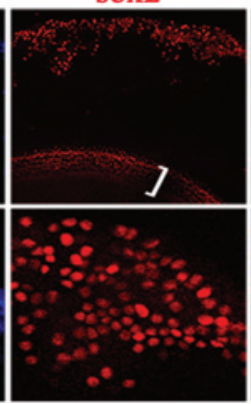

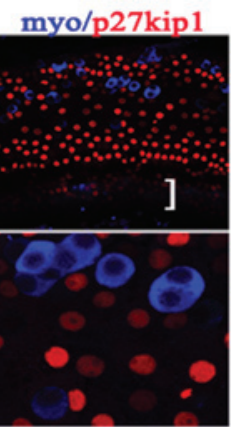

myo/sox 2

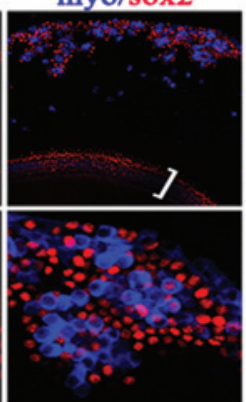

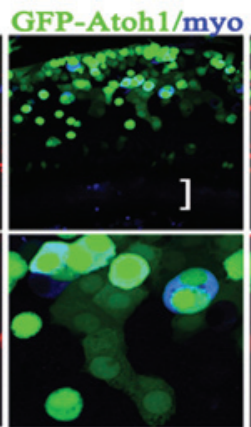

GFP-Atoh 1/myo

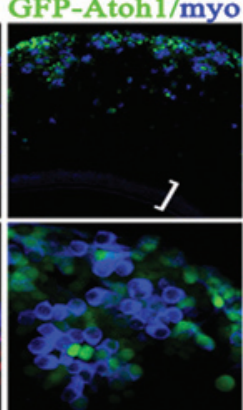

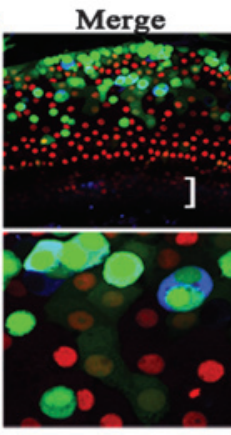

Merge

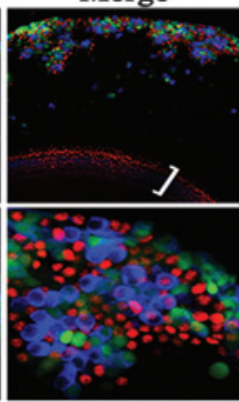

Figure 5. Atoh1 expression defines the fate of LER cells. (A) Explants at 0.8x108 PFU/ml on 3 DVI. A number of GFP-positive LER cells (green) were already myosin7A positive (blue), while others were p27kip1 positive (red). (B) Magnified images from (A). (C) Explants at 0.8x10 ${ }^{8}$ PFU/m1 at 7 DVI. A number of GFP-positive LER cells (green) were already myosin7A positive (blue), while sox2-positive cells (red) surrounded the EHCLCs. (D) Magnified images from (C). Scale bar: $50 \mu \mathrm{m}$ in (A) and (C); $20 \mu \mathrm{m}$ in (B) and (D). Atoh1, Atonal homolog1; EHCLCs, ectopic hair-cell-like cells; LER, lesser epithelial ridge; Ad5, human adenovirus serotype 5; DVI, days after viral infection.

number of the infected LER cells (EGFP positive) transformed to hair-cell-like cells (myosin7A positive) with an oblong or round shape, whereas other cells remained nonsensory epithelial cells (p27kip1) with a polygonal, flat shape (Fig. 5A and B). Furthermore, many myosin7A-positive cells clustered in the LER with sox2-positive cells surrounding them, indicating that hair-cell-like cells may induce supporting cell formation (Fig. 5C and D).

\section{Discussion}

The human Ad5 vector, encoding both Atoh1 and the reporter gene EGFP, is a useful tool for new hair cell production due to its high transfection efficiency, low level of target tissue damage and ease of control $(6-12,14)$. The viral titration in the present study indicated that appropriate titers induce optimal Atoh1 expression. At titers $>2.4 \times 10^{8} \mathrm{PFU} / \mathrm{ml}$, cochlear cultured explants may be severely damaged. At titers $<0.16 \times 10^{8} \mathrm{PFU} / \mathrm{ml}$, although weak Atoh1 expression was observed, it was not sufficient to generate ectopic hair cell formation. Our data indicate that $0.4-1.6 \times 10^{8} \mathrm{PFU} / \mathrm{ml}$ Ad5-EGFP-atohl is an efficient and safe titer range for hair-cell-like cell formation in cultured cochlear explants.

At titers of $0.16-1.6 \times 10^{8} \mathrm{PFU} / \mathrm{ml}$, higher infection efficiency and expression levels were observed (Fig. 1). GFP alone did not induce EHCLCs expression, whereas Ad5-EGFP-atoh1 did induce robust EHCLCs formation. Thus, EHCLCs formation in the LER was Atoh1 expression dependent. At titers $<0.1 \times 10^{8} \mathrm{PFU} / \mathrm{ml}$, although a number of weakly GFP-positive cells were identified, no myosin7A-positive cells were detected, even at 11 DVI. At titers of $0.4 \times 10^{8} \mathrm{PFU} / \mathrm{ml}$ Ad5-EGFP-atoh1, only $\sim 4 \%$ of atohl-infected cells converted to hair-cell-like cells by 5 DVI in the LER. At titers of $1.6 \times 10^{8} \mathrm{PFU} / \mathrm{ml}, \sim 54 \%$ of atohl-infected cells converted to hair cell-like cells. These data suggest that hair cell formation requires a certain level of Atoh1, with higher expression inducing more hair cell-like cell formation.

At $0.4-1.6 \times 10^{8} \mathrm{PFU} / \mathrm{ml}$ Ad5-EGFP-atoh1, EHCLC formation increased with time. At $0.4 \times 10^{8} \mathrm{PFU} / \mathrm{ml}$, EHCLC formation required 5 days. However, at $1.6 \times 10^{8} \mathrm{PFU} / \mathrm{ml}$, ectopic hair cell formation only required 2.5 days. Thus, greater Atoh1 expression shortens the time required for EHCLC formation. Furthermore, the number of EHCLCs increased with time but then ceased increasing at 7 DVI for all titers. Even at $1.6 \times 10^{8} \mathrm{PFU} / \mathrm{ml}$, only $\sim 71 \%$ of Ad5-EGFP-atohl-infected cells in the LER transdifferentiated into hair cell-like cells. The fate of the non-differentiated cells may help explain this phenomenon.

The data from the present study further revealed that hair cell formation requires a certain Atoh1 expression level; if it was too low, the LER did not convert into hair cell-like cells. A number of Ad5-EGFP-atohl-infected LER cells (EGFP positive) had already converted to hair cell-like cells (myosin7A positive) with an oblong or round shape at 3 DVI, while the other LER cells remained nonsensory epithelial cells (p27kip1 positive) with a polygonal, flat shape (Fig. 5A and B). At 3 DVI, the majority of myosin7A-positive cells exhibited a strong green fluorescence and p27kip1-positive cells appeared to have weak or no green fluorescence. However, numerous myosin7A-positive cells were observed clustered in the LER with sox2-positive cells surrounding them (Fig. 5C and D), indicating that hair cell-like cells induce supporting cell formation, which has also been previously reported (10). Therefore, the majority of Ad5-EGFP-atohl-infected LER 
cells (with sufficient Atoh1 expression) converted into hair cells and induced the surrounding nonsensory epithelial cells to transform into supporting cells.

In the present study, an appropriate virus titer range for infecting cultured cochlear explants was examined, providing highly efficient infection and conversion rates but reducing the infection side effects. Atoh1 expression is critical to hair cell formation, as it defines the fate of LER cells as either hair cell-like cells or nonsensory epithelial cells. The present study provides an important guideline for future investigations to develop novel gene therapy strategies in the treatment of deafness.

\section{Acknowledgements}

This study was supported by the following: Major State Basic Research Development Program of China (973 Program) (2011CB504500, 2011CB504506) to H. L.; NSFC grant 81028003/H1305 to P. C and F. C.; Key Basic Research Project of Shanghai Committee of Science and Technology (no. 10JC1402500) to F. C.; 81200740/ H1304 to J. Y.; Innovation Program of Shanghai Committee of Science and Technology (no. 11411952300) to F. C.

\section{References}

1. Corwin JT and Cotanche DA: Regeneration of sensory hair cells after acoustic trauma. Science 240: 1772-1774, 1988.

2. Ryals BM and Rubel EW: Hair cell regeneration after acoustic trauma in adult Coturnix quail. Science 240: 1774-1776, 1988.

3. Bermingham NA, Hassan BA, Price SD, Vollrath MA, Ben-Arie N, Eatock RA, et al: Math1: an essential gene for the generation of inner ear hair cells. Science 284: 1837-1841, 1999.
4. Chen P, Johnson JE, Zoghbi HY and Segil N: The role of Math1 in inner ear development: Uncoupling the establishment of the sensory primordium from hair cell fate determination. Development 129: 2495-2505, 2002.

5. Gubbels SP, Woessner DW, Mitchell JC, Ricci AJ and Brigande V: Functional auditory hair cells produced in the mammalian cochlea by in utero gene transfer. Nature 455: 537-541, 2008.

6. Han Z, Yang JM, Chi FL, Cong N, Huang YB, Gao Z, et al: Survival and fate of transplanted embryonic neural stem cells by Atoh1 gene transfer in guinea pigs cochlea. Neuroreport 21: 490-496, 2010.

7. Huang Y, Chi F, Han Z, Yang J, Gao W and Li Y: New ectopic vestibular hair cell-like cells induced by Math1 gene transfer in postnatal rats. Brain Res 1276: 31-38, 2009.

8. Izumikawa M, Minoda R, Kawamoto K, Abrashkin KA, Swiderski DL, Dolan DF, et al: Auditory hair cell replacement and hearing improvement by Atoh 1 gene therapy in deaf mammals. Nat Med 11: 271-276, 2005.

9. Kawamoto K, Ishimoto S, Minoda R, Brough DE and Raphael Y: Math1 gene transfer generates new cochlear hair cells in mature guinea pigs in vivo. J Neurosci 23: 4395-4400, 2003.

10. Woods C, Montcouquiol M and Kelley MW: Math1 regulates development of the sensory epithelium in the mammalian cochlea. Nat Neurosci 7: 1310-1318, 2004.

11. Yang J, Bouvron S, Lv P, Chi F and Yamoah EN: Functional features of trans-differentiated hair cells mediated by Atoh1 reveals a primordial mechanism. J Neurosci 32: 3712-3725, 2012.

12. Yang J, Cong N, Han Z, Huang Y and Chi F: Ectopic hair cell-like cell induction by Math1 mainly involves direct transdifferentiation in neonatal mammalian cochlea. Neurosci Lett 549: 7-11, 2013.

13. Yang SM, Chen W, Guo WW, Jia S, Sun JH, Liu HZ, et al: Regeneration of stereocilia of hair cells by forced Atoh1 expression in the adult mammalian cochlea. PLoS One 7: e46355, 2012

14. Zheng JL and Gao WQ: Overexpression of Math1 induces robust production of extra hair cells in postnatal rat inner ears. Nat Neurosci 3: 580-586, 2000.

15. Pan N, Jahan I, Kersigo J, Duncan JS, Kopecky B and Fritzsch B: A novel Atoh1 'self-terminating' mouse model reveals the necessity of proper Atoh1 level and duration for hair cell differentiation and viability. PLoS One 7: e30358, 2012. 